\title{
Expression of neural cell adhesion molecule (NCAM) isoforms in neuroblastoma
}

\author{
E Phimister, F Kiely, J T Kemshead, K Patel
}

\begin{abstract}
A comparative study on the expression of the neural cell adhesion molecule (NCAM) in human neuroblastoma cell lines and tissues was undertaken. NCAMs are a family of closely related cell surface glycoproteins involved in cell-cell interactions. Using antibodies that recognise distinct epitopes on NCAM, their presence was shown in neuroblastoma, but these studies do not yield any information on the specific NCAM isoforms associated with the tumour. Western and Northern blot analyses were therefore carried out to characterise the NCAM isoforms in this neuroectodermal tumour. Western blot studies using the monoclonal antibody ERIC-1 showed that all human neuroblastoma cell lines tested expressed the 140 and 120 kilodalton isoforms of NCAM in their desialo state. Some of the cell lines also expressed NCAM-180. The data are corroborated by Northern blotting where a transcript of $\mathbf{7 \cdot 4}$ kilobase pairs was identified only in lines expressing NCAM-180; the 6.7 and 5.4 kilobase pair transcripts coding for 140 and 120 kilodalton isoforms, respectively, were present in all the cell lines tested. The NCAM isoforms identified in neuroblastoma were also different from those found in adult and fetal brain tissue, suggesting that aberrations are expressed in the molecule during tumorigenesis.
\end{abstract}

NCAMs are a family of closely related glycoproteins described as being involved in cell to cell interactions during growth and development.' The expression of these molecules is widespread in all three germ layers during embryogenesis, but becomes restricted in adults. NCAMs have been described on a variety of human tumours that do not arise from the neuroectoderm. These include rhabdomyosarcoma (Patel K, Kemshead JT, unpublished observations), Wilms' tumour, ${ }^{23}$ Ewing's sarcoma ${ }^{4}$ and some primitive myeloid malignancies. ${ }^{5}$

NCAMs in man arise from the differential splicing and use of alternative polyadenylation sites of a single gene found on chromosome 11 at q23. ${ }^{6}$ In all, five different isoforms discernible on Western blots have been described in the brain. Three membrane associated forms have been well characterised. These are
NCAM 180 and NCAM 140 which are transmembrane glycoproteins with differing lengths of cytoplasmic tails, and NCAM 120, which is linked into the membrane via a glycosylphosphoinositol (GPI) anchor. ${ }^{1}$ A secretory protein of 115 kilodaltons has been identified. The characterisation of two further isoforms of NCAM (170 and 95 kilodaltons) remain poor at present. In skeletal muscle, a different spectrum of NCAMs have been identified: a 140 kilodalton transmembrane protein has been identified along with two GPI linked proteins of 155 and 125 kilodaltons and a secretory isoform of 115 kilodaltons. Further diversity in the expression of NCAMs on muscle and neural tissue is brought about by differential glycosylation. ${ }^{1}$ In the embryo NCAM is highly sialylated and as a consequence appears as a smear on Western blots, whereas less sialylation occurs in adults. ${ }^{1}$

Despite considerable efforts being undertaken to characterise NCAM expression on normal tissue, less information is available on the spectrum of isoforms found on human tumours. ${ }^{8}$ Using an antibody to polysialic acid, Roth et al have shown the embryonic form of the molecule on Wilms' tumour. Lipinski et al have characterised NCAM expression on the human neuroblastoma cell line IMR $32,{ }^{4}$ and Figarella-Branger et al have recently reported that neuroblastoma expresses the embryonic form of NCAM. ${ }^{9}$

In this paper we extended these observations using both Northern blot and Western blot analysis. All lines and tissues investigated express the embryonic forms of NCAM. After removal of sialic acid residues, however, a heterogeneity in NCAM expression is detected. Furthermore, neuroblastomas seem to express selective isoforms of NCAM compared with human fetal and adult brain.

\section{Methods}

CELL LINES

The human neuroblastoma cell lines Kelly, ${ }^{10}$ SK-N-BE(2C) (kindly donated by Dr L Helson, New York Medical College), IMR32," ${ }^{11}$ SK-N-SH, ${ }^{12} \mathrm{NB}^{1,{ }^{13}}$ GOTO $^{14}$ the human neuroepithelioma line CHP100 ${ }^{15}$ and the $\mathrm{T}$-cell line $\mathrm{GH} 1^{16}$ were grown in a $5 \%$ carbon dioxide incubator using RPMI 1640 medium supplemented with $10 \%$ fetal calf serum, $2 \mathrm{mM}$ glutamine, $100 \mathrm{IU} / \mathrm{ml}$ penicillin, and $100 \mu \mathrm{g} / \mathrm{ml}$ streptomycin. When approaching confluency, cells were passaged using trypsin/versene to remove adherent neuroblastoma lines from the dishes. All 
Figure 1 Binding of NCAM antibodies to human neuroblastoma cell lines. Samples were examined by both light microscopy and $a$

fluorescein activated cell sorter. $(i)$ Cells incubated with FITC rabbit antimouse Ig alone. (ii) Cells incubated with anti$N C A M$ antibody and FITC rabbit anti-mousc Ig.
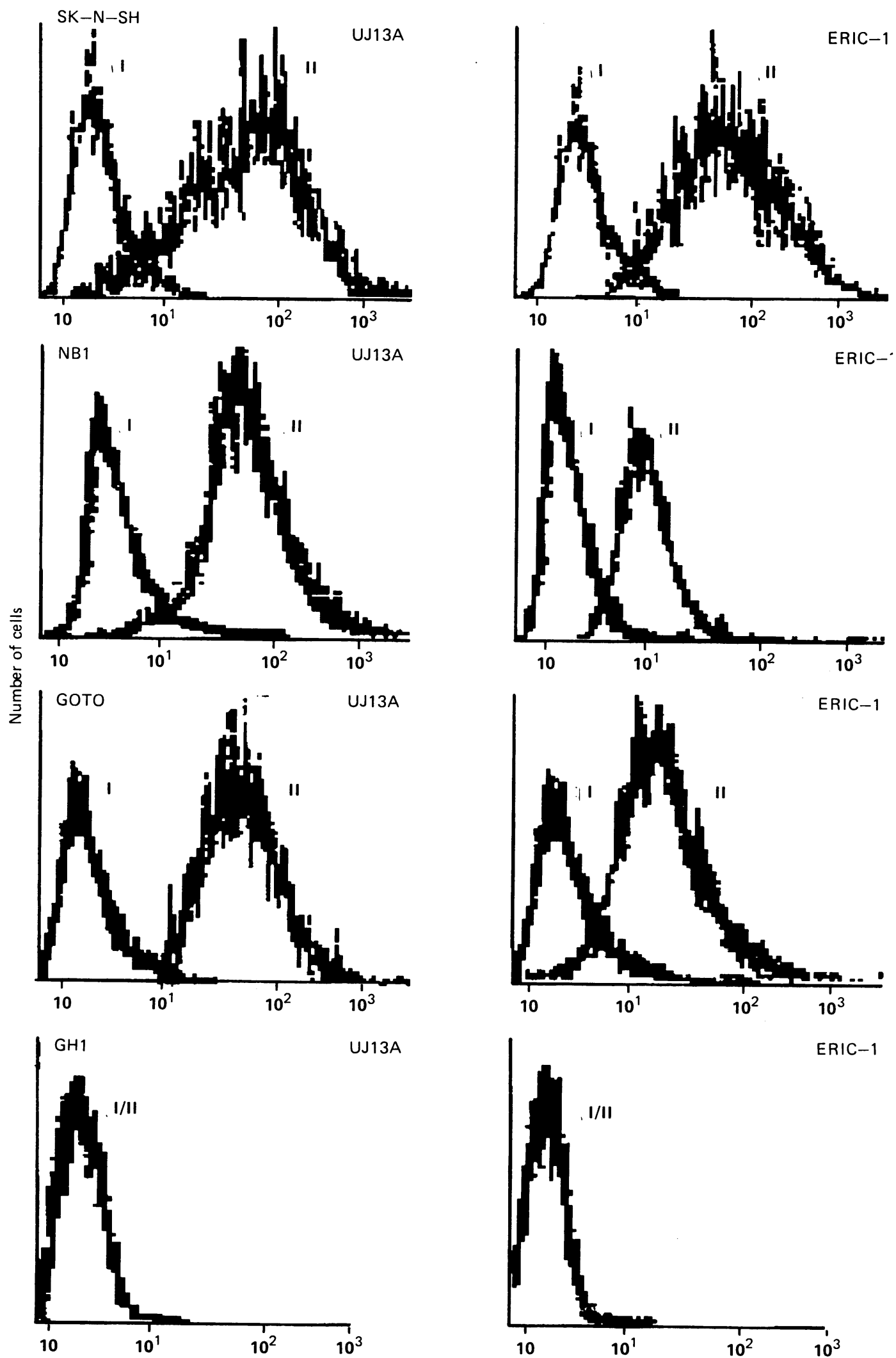

UJ13A

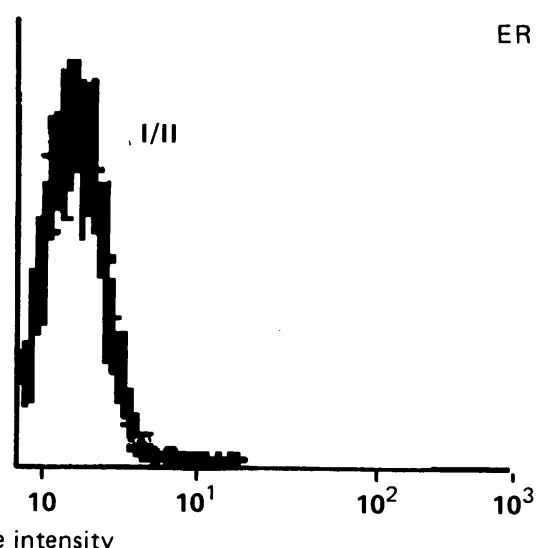

Relative fluorescence intensity

experiments were undertaken on cells while in the exponential growth phase.

\section{INDIRECT IMMUNOFLUORESCENCE/FACS}

ANALYSIS

Neuroblastoma cells were scraped from dishes using a rubber policeman. To facilitate disaggregation, cells were incubated in $2 \mathrm{mM}$ ethylenediaminetetra-acetic acid (EDTA) in phosphate buffered saline (PBS) containing $1 \%$ human serum albumin at $37 \mathrm{C}$ for five minutes. After washing, cells were incubated with either ERIC-1, UJ13A, or PBS for one hour at $4 \mathrm{C}$. Cells were washed to remove unbound antibody and subsequently incubated with fluorescein (FITC) conjugated rab- 
Figure 2 NCAM expression on human neuroblastoma cell lines. The size of the NCAM isoforms identified was determined by comparison with Amersham

International Rainbow molecular weight markers: 200 myosin, $116 \beta$-galactosidase 95 phosphorylase- $\beta$, 69 bovine serum albumin, 46 ovalbumin, 30 carbonic anhydrase.

(A) Cell extracts without neuraminidase treatment $+M \mid A E R I C$ 1. (B) Cell extracts with neuraminidase treatment $+M / A$ ERIC-1.

(C) Cell extracts with neuraminidase treatment + Irrelevant M/A M340

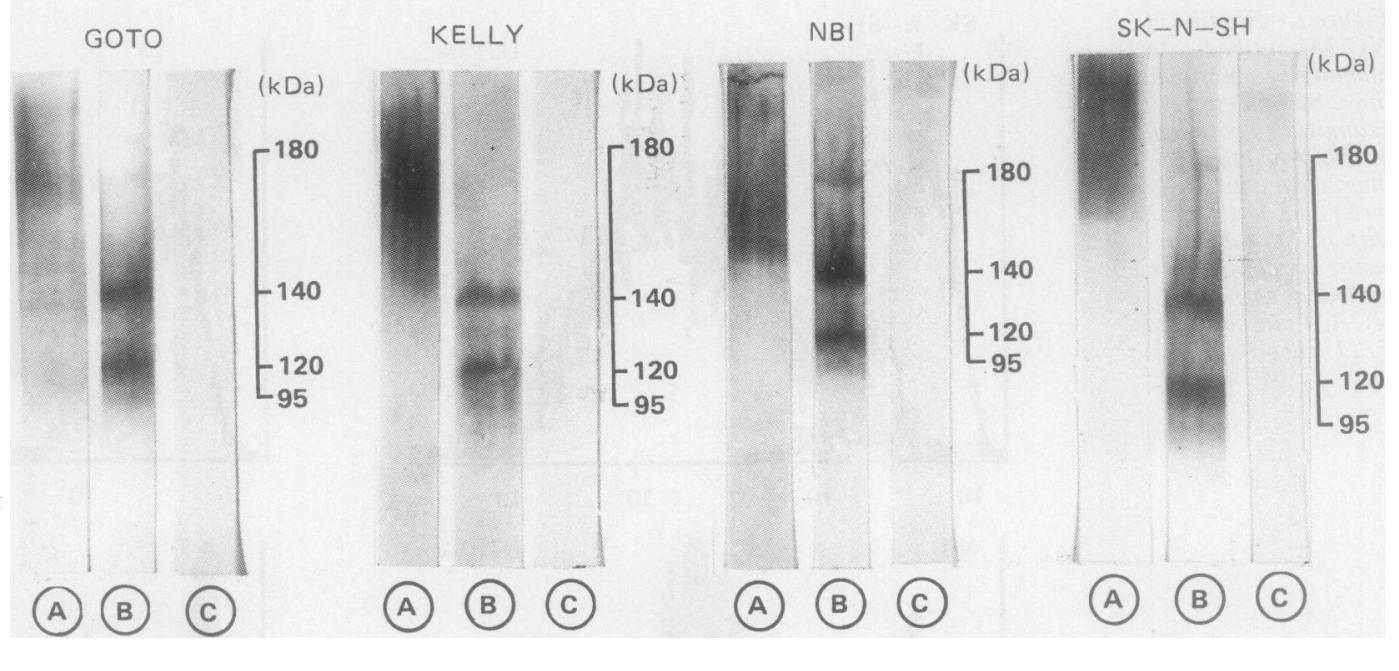

bit anti-mouse Ig under the same conditions. Cells were examined by using a Zeiss fluorescence microscope with epi-illumination optics and by a fluorescence activated cell sorter (FACS).

\section{MONOCLONAL ANTIBODIES}

Monoclonal antibody $\mathrm{UJ}_{13 \mathrm{~A}^{17}}$ was raised against 16 week human fetal brain and ERIC-1 against human retinoblastoma. ${ }^{18}$ Both antibodies recognise distinct epitopes on the human neural cell adhesion molecule. ${ }^{19}$ ERIC1 was used for cell biochemical studies as, unlike UJ13A, it can be used for Western blot analysis.

\section{NORTHERN BLOT ANALYSIS}

Total RNA $10 \mu \mathrm{g}$ was separated on a $1 \%$ agarose/formaldehyde gel by electrophoresis. The RNA was transferred to GeneScreen Plus and the filters baked at $80^{\circ} \mathrm{C}$ for two hours and prehybridised with salmon sperm DNA ( $0 \cdot 1$ $\mathrm{mg} / \mathrm{ml}$ ) for four hours at $60^{\circ} \mathrm{C}$.

Blots were hybridised with a human NCAM cDNA probe $(\lambda 9.5$ labelled by random priming) at $60^{\circ} \mathrm{C}$ for 18 hours. Filters were washed to a final stringency of $0.1 \times$ SSC, $1 \%$ sodium dodecyl sulphate at room temperature and exposed to a pre-flashed Fuji $x$-ray film, with intensifying screens at $-70^{\circ} \mathrm{C}$ for an appropriate period.

SDS-PAGE AND WESTERN BLOT ANALYSIS

Cells were solubilised in sample buffer consisting of $0.1 \mathrm{M}$ TRIS-HCl, $\mathrm{pH} 6.8,2 \% \mathrm{SDS}$, $10 \%$ glycerol, $2 \mathrm{mM}$ PMSF, $2 \mathrm{mM}$ EDTA and $10 \mu \mathrm{g} / \mathrm{ml}$ leupeptin. DNA was sheared by passing the lysate through a series of needles and the lysate boiled for three minutes after addition of dithiothreitol to a final concentration of $0 \cdot 1 \mathrm{M}$.

Sodium dodecyl sulphate polycrylamide gel electrophoresis (SDS-PAGE) was performed using a $120 \times 140 \times 1.5 \mathrm{~mm}, 7 \%$ acrylamide gel at 250 volts for five hours at room temperature. Visible rainbow protein molecular weight markers (corresponding to 14.3-200 kilodaltons) (Amersham International) were used as a reference for estimating the molecular weight of the separated proteins. After blotting, the filter was incubated in 5\% Marvel (in PBS) overnight to block non-specific binding sites.

Membrane strips were incubated with either ERIC-1 antibody $(26 \mu \mathrm{g} / \mathrm{ml})$ or an irrelevant antibody at the same concentration for 30 minutes at room temperature. The strips were individually washed twice for five minutes in PBS. After subsequent incubations with alkaline phosphatase-conjugated rabbit antimouse Ig for 30 minutes at room temperature, the strips were again washed twice in PBS and once in TRIS-buffered saline containing $1 \mathrm{mM}$ Levamisole. The strips were developed by incubating for 15 minutes at room temperature in the dark with a filtered solution containing $1 \mathrm{mM}$ Levamisole, $0.5 \mathrm{mM}$ naphthol AS-MX phosphate, $2 \% \mathrm{~N}, \mathrm{~N}$-dimethylformamide $0 \cdot 1 \mathrm{M}$ TRIS (pH 8.2) and $4 \mathrm{mM}$ Fast Red TR salt (Sigma).

\section{Results}

Monoclonal antibodies UJ13A and ERIC-1 bind to most human neuroblastomas studied, as determined by indirect binding assays, although some heterogeneity in the degree of staining is detected both within and between the different cell lines. Figure 1 shows the typical binding observed with these antibodies as determined by FACS analysis. The calculated mean fluorescence intensity obtained with lines NB1 and GOTO was 293 and 353 (medians 278 and 330) for antibody UJ13A and 219 and 237 (medians 209 and 216) for ERIC-1.

In contrast, $\mathrm{SK}-\mathrm{N}-\mathrm{SH}$ binds slightly more antibody with mean and median fluorescent values of 409 (median 380) and 307 (median 275) recorded for UJ13A and ERIC-1, respectively. None of the cell lines examined bound anti-mouse $\mathrm{Ig}$ in the absence of a specific monoclonal antibody as the signal seen by FACS analysis was equivalent to that when the $T$ cell line GH1 was incubated with either UJ13A or ERIC-1 (fig 1). Similar staining profiles to those reported here were also IMR32, SK-N-BE(2C), Kelly and the observed with the human neuroblastoma lines 
Table 1 NCAM isoforms identified in human neuroblastoma cell lines

\begin{tabular}{lcccc}
\hline & \multicolumn{3}{l}{$\begin{array}{l}\text { After neuraminidase treatment } \\
\text { (kilodaltons) }\end{array}$} \\
\hline CHP100 & & 140 & 120 & 95 \\
NB1 & 180 & 140 & 120 & 95 \\
Kelly & 180 & 140 & 120 & 95 \\
SK-N-SH & 140 & 120 & 95 \\
IMR32 & 180 & 140 & 120 & 95 \\
GOTO & & 140 & 120 & 95 \\
SK-N-BE(2C) & & 140 & 120 & 95
\end{tabular}

All lines show the embryonic form of NCAM before neuraminidase digestion.

neuroepithelioma line CHP100 with the calculated mean and median fluorescent windows lying within the range of 190 and 403 for both antibodies. Incubation of all neuroblastoma cell lines with an irrelevent monoclonal antibody also gave a signal analogous to that seen with FITC rabbit anti-mouse Ig alone.

\section{WESTERN BLOT ANALYSIS}

Extracts of all the human neuroblastoma cell lines examined produced smears on Western blots ranging in size from $140>300$ kilodaltons following staining with the NCAM antibody ERIC-1. No binding was observed with an irrelevant antibody known not to bind to NCAM (fig 2). Once the membrane proteins have been partially deglycosylated with neuraminidase, distinct patterns of NCAM isoform expression were shown. The neuroblastoma lines NB1, SK-N-SH, and IMR32 express the $180,140,120$, and 95 (weakly) kilodalton isoforms of the molecule, whereas GOTO, SK-N-BE(2C) and the neuroepithelioma line CHP100 express only the 140,120 and 95 kilodalton proteins. Representative blots of four cell lines are shown in fig 2 and a compilation of all of the data in table 1 .

To confirm the above findings mRNA was obtained from the cell lines and after size separation and blotting, probed with the human NCAM probe $\lambda$ 9.5. For brevity, representative blots are presented in fig 3 along with a summary of the data for all the lines in table 2. Only those lines expressing the 180 kilodalton protein were found to contain the $7 \cdot 4$ kilobase pair NCAM mRNA coding for this isoform of the molecule. The 6.7 and 5.4

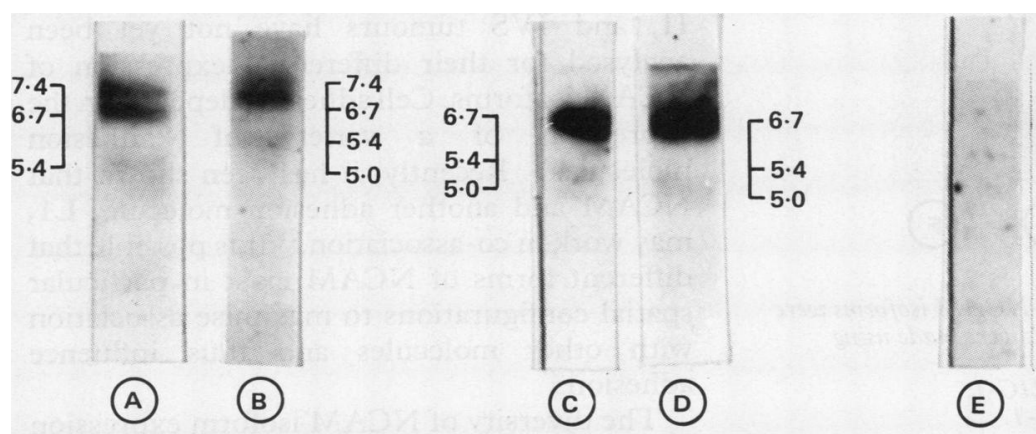

Figure 3 NCAM mRNA species detected in human neuroblastoma. Molecular weights of NCAM mRNAs were determined by comparison with markers produced from a Hind III $/ O X-174$ DNA-Hae III digest (Pharmacia).

(A) NB1; (B) SK-N-SH; (C) GOTO; (D) Kelly; (E) GH1-T cell line.
Table 2 NCAM mRNA identified in human neuroblastoma cell lines

\begin{tabular}{|c|c|c|c|c|}
\hline \multicolumn{5}{|c|}{ Kilobase pairs } \\
\hline $\begin{array}{l}\text { CHP100 } \\
\text { NB1 } \\
\text { Kelly } \\
\text { SK-N-SH } \\
\text { IMR32 } \\
\text { GOTO } \\
\text { SK-N-BE(2C) }\end{array}$ & $\begin{array}{l}7 \cdot 4 \\
7 \cdot 4\end{array}$ & $\begin{array}{l}6 \cdot 7 \\
6 \cdot 7 \\
6 \cdot 7 \\
6 \cdot 7 \\
6 \cdot 7 \\
6 \cdot 7 \\
6 \cdot 7\end{array}$ & $\begin{array}{l}5 \cdot 4 \\
5 \cdot 4 \\
5 \cdot 4 \\
5 \cdot 4 \\
5 \cdot 4 \\
5 \cdot 4 \\
5 \cdot 4\end{array}$ & $\begin{array}{l}5 \cdot 0 \\
5 \cdot 0 \\
5 \cdot 0\end{array}$ \\
\hline
\end{tabular}

kilobase pair mRNA species coding for the 140 and 120 kilodalton isoforms were found in all the cell lines examined. The signal identifying the 6.7 kilobase pair species was, in general, more intense than that seen at 5.4 kilobase pairs. In the CHP100, NB1, SK-N-SH, GOTO and SK-N-BE(2C) cell lines a faint band of 5.0 kilobase pairs was identified. The nature of this band is unclear, although we believe that this is not due to cross-hybridisation of the NCAM probe with ribosomal RNA. Repeating the Northern blots with poly-dT affinity purified mRNA still showed the presence of the 5.0 kilobase pairs species.

In total, six human neuroblastoma tissues have been examined for differential NCAM expression with representative samples are shown in fig 4 . In the absence of neuraminidase treatment to remove polysialic acid residues from membrane glycoproteins, a smear was observed on the Western blots analogous to that found with the cell lines. After deglycosylation, two patterns of expression have been noted which again parallel the results observed with the cell lines. No relation between stage of tumour and NCAM expression was apparent in this study as all the tumours were from patients with stage IV disease. Northern blot analysis was not possible on these samples as the RNA within the tissue was found to be degraded.

Human fetal brain tissue also expresses the embryonic form of human NCAM as a smear ranging from 140 to about 300 kilodaltons is observed on Western blot analysis using monoclonal antibody ERIC-1. Neuraminidase treatment of the extracts, however, shows a different pattern of isoform expression to that seen in neuroblastoma. Four distinct bands of about $180,170,140$, and 120 kilodáltons are seen along with a weaker band of about 95 and 65 kilodalton (fig 5). This is the pattern of NCAM expression observed in adult brain before neuraminidase treatment, indicating that the molecule is less sialylated. Neuraminidase treatment reduces the size of the five bands, reflecting marginal sialylation of these isoforms.

\section{Discussion}

Antibody UJ13A, and, to a lesser extent, ERIC-1, have been used as a diagnostic aid in the differential diagnosis of neuroblastoma from other childhood malignancies, particularly acute lymphoblastic leukaemia. ${ }^{20}$ UJ $13 A$ has also been used in conjunction with other antibodies for the identification of neuroblastoma cells in bone marrow and their subsequent removal. ${ }^{21}$ Immunocytochemical tech- 


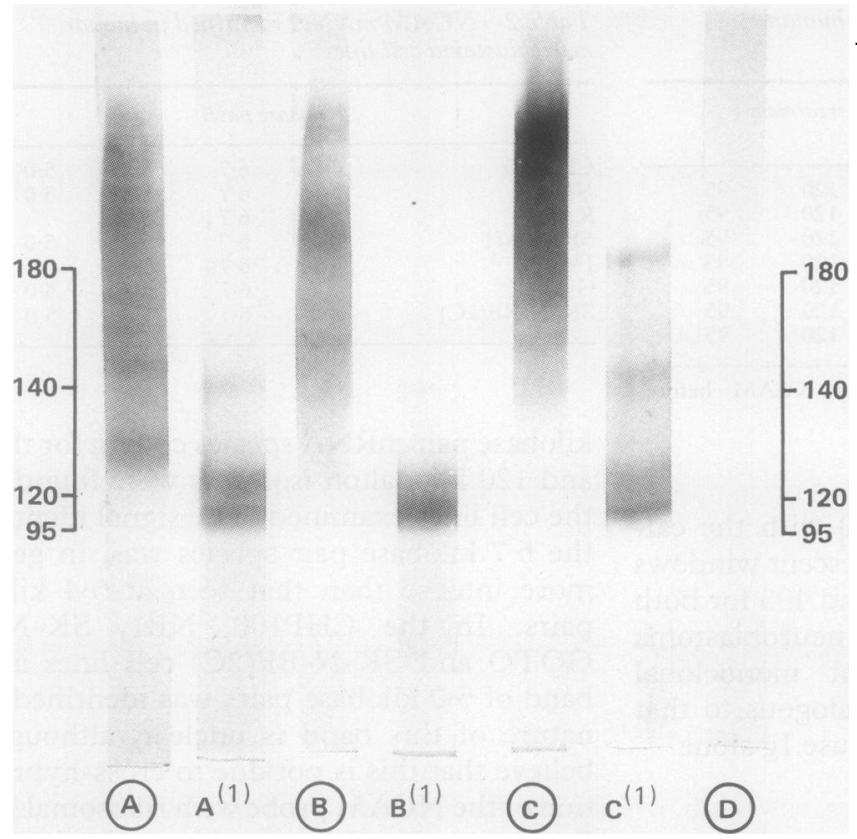

Figure 4 Heterogeneity in NCAM expression in human neuroblastoma tissue. NCAM isoforms were detected using the monoclonal antibody ERIC-1 and compared with standard molecular weight markers (fig 2).

( $A-C)$ Samples without neuraminidase treatment $+M / A E R I C-1\left(A^{(1)}-C^{(1)}\right)$ Samples with neuraminidase treatment $+M / A$ Eric-1 (D) Samples incubated with neuraminidase and irrelevant $M / A M 340$.

niques have been independently shown to be the most sensitive way of identifying low levels of tumour infiltration in bone marrow aspirates. ${ }^{22}{ }^{23}$ The usefulness of these reagents comes not from their unique binding to neuroblastoma, but rather from the high number of neuroblastomas recognised by the two antibodies and the intensity of the signal

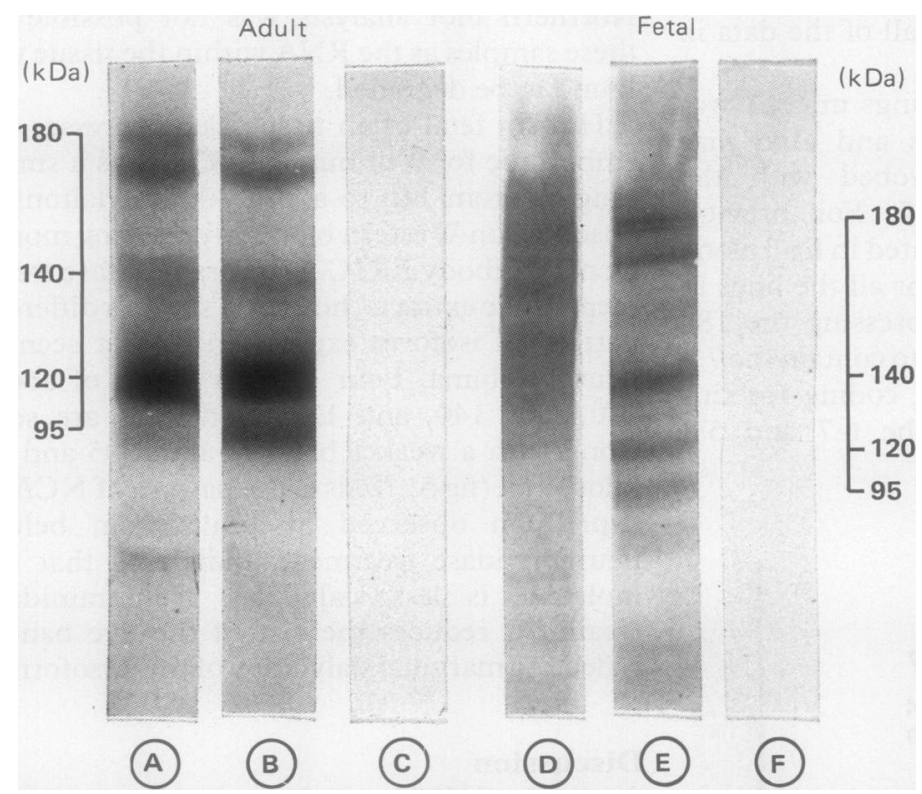

Figure 5 NCAM expression on human adult and fetal brain. NCAM isoforms were detected using the monoclonal antibody ERIC-1. Size estimates were made using standard molecular weight markers (fig 2).

(A) Adult brain without neuraminidase treatment $+M / A$ ERIC-1

(B) Adult brain with neuraminidase treatment $+M / A E R I C-1$

(C) Adult brain with neuraminidase treatment $+M / A M 340$.

(D) Fetal brain without neuraminidase treatment $+M / A$ ERIC-1.

(E) Fetal brain with neuraminidase treatment $+M / A$ ERIC-1.

(F) Fetal brain with neuraminidase treatment $+M / A M 340$. observed using a variety of indirect binding assays. Figure 1 shows representative data on the binding of UJ13A and ERIC-1 to three of six neuroblastoma cell lines and one human neuroepithelioma cell line. While there is some variation in the intensity of staining, both within and between cell lines, the signals observed are considerably greater than those observed with leukaemic cell lines such as GH1 where no fluorescence can be detected by light microscopical examination.

The finding that UJ13A and ERIC-1 antibodies bind to human NCAM has enabled us to investigate what diversity of NCAM expression is found in human neuroblastoma cell lines and tissues. All samples analysed exhibited the embryonic form of the molecule as determined by the degree of smearing shown on the gels. These results were confirmed by a similar staining pattern obtained with a monoclonal antibody recognising polysialic acid (data not shown). Neuraminidase treatment to strip partially carbohydrate residues from proteins showed a heterogeneity in the isoforms of NCAM expressed on both tumours and tissues. All cell lines expressed the 140 and 120 kilodaltons isoforms of the molecule along with a weak band observed on the gels at 95 kilodaltons. Only the neuroblastoma lines NB1, IMR32, and SK-N-SH express the 180 kilodalton isoform and no expression of the 170 kilodalton protein was detected (fig 2) (table 1). These results were mimicked by the heterogeneity in NCAM expression in the six stage IV neuroblastomas examined (fig 4) (table 2). Furthermore, the data on the human neuroblastoma cell lines were confirmed by Northern blot analysis. In these blots an additional weak band of 5.0 kilobase pairs was observed in some of the cell extracts which has not been reported to code for any of the known isoforms of NCAM. The nature of this band remains unclear, although it has also recently been identified in small cell carcinoma cell lines and tumour tissues (Duilinhoven $\mathbf{M}$, personal communication). Northern blot analysis was not possible for the fresh neuroblastoma samples as they were taken from patients after combination chemotherapy where the quality of the RNA was insufficient for these studies.

The functional importance of the differential expression of NCAM isoforms on neuroblastoma tissue is not clear. Whether this affects their metastatic potential remains unknown. Unfortunately, due to a lack of tissue, stages I, II, and IVS tumours have not yet been analysed for their differential expression of NCAM isoforms. Cell adhesion depends on the expression of a variety of "adhesion molecules". Recently, it has been shown that NCAM and another adhesion molecule, L1, may work in co-association..$^{25}$ It is possible that different forms of NCAM exist in particular spatial configurations to maximise association with other molecules and thus influence adhesion.

The diversity of NCAM isoform expression is potentially greater than indicated above. It is known that in some NCAM species differential splicing occurs to allow the insertion of mini- 
exons into the molecule. For example, a 35 amino acid sequence (designated the MSD1 region) has been described as being inserted specifically in skeletal muscle NCAM between the regions coded for by exons 12 and 13 . If this region was only expressed in tumours of rhabdoid origin, it would represent a unique marker to aid in the characterisation of these tumours. The expression of the MSD1 region and other tissue specific mini-exons is currently under review in both paediatric solid tumours and primary intracranial malignancies. Preliminary investigations also suggest that it may be possible to characterise neuroblastoma from rhabdoid tumours on the basis of isoform expression and the insertion/deletion of mini exons. Similarly, all medulloblastomas examined to date express an NCAM pattern similar to that found in human fetal brain. ${ }^{1824}$ Consequently, expression of the 170 kilodalton isoform of NCAM could help distinguish these from the rare intracranial neuroblastomas. From these studies it is, therefore, apparent that simple indirect immunofluorescence studies on tumours such as neuroblastoma do not allow the biochemical diversity in antigen expression to be fully evaluated. It is hoped that by examining the pattern of NCAM expression, at both the gross biochemical and molecular level, interesting information relating to the diagnostic potential of these findings will ensue along with further insights into the biology of neuroblastoma.

We thank the Imperial Cancer Research Fund and the Neuroblastoma Society for funding this project, and Professo Frank Walsh, Guy's Hospital, London for kindly supplying the NCAM probe Lambda $9 \cdot 5$. We also thank Miss S Murphy for typing the manuscript.

1 Cunningham BA, Hemperly JJ, Murray BA, Prediger EA, Brackenbury R, Edelman GM. Neural cell adhesion molecule: structure, immunoglobulin-like domains, cell surface modulation, and alternative RNA splicing. Science 1987;236:799-806.

2 Roth J, Zuber C, Wagner P, Blaha I, Bitter-Suermann D, Heitz PU. Presence of the long chain form of polysialic Identification of a cell adhesion molecule as an oncodevelopmental antigen and implications for tumor histogenesis. Am J Pathol 1988;133:227-40.

3 Roth J, Zuber C, Wagner P, et al. Re-expression of poly(sialic acid) units of the neural cell adhesion molecule poly(sialic acid) units of the neural cell adhesion molecule
in Wilms tumor. Proc Natl Acad Sci USA 1988;85: in Wilms t $2999-3003$.

4 Lipinski M, Hirsch M-R, Deagostini-Bazin H, Yamada O, Tursz T, Goridis C. Characterization of neural cel adhesion molecules (NCAM) expressed by Ewing and neuroblastoma cell lines. Int J Cancer 1987;40:81-6.

5 Lanier LL, Testi R, Bindl J, Phillips JH. Identity of Leu-19
(CD56) leucocyte differentiation antigen and neural cell adhesion molecule. J Exp Med 1989;169:2233-8.

6 Nguyen C, Mattei M-G, Mattei J-F, Santoni M-J, Goridis C, Jordan BR. Localization of the human NCAM gene to band q23 of chromosome 11: the third gene coding for a cell interaction molecule mapped to the distal portion of the long arm of chromosome 11.J Cell Biol 1986;102: the long

7 Walsh FS, Dickson G. Generation of multiple N-CAM polypeptides from a single gene. Bioessays 1989;11:83-8.

8 Roth J, Blaha I, Bitter-Suermann D, Heitz PU. Blastemal cells of nephroblastomatosis complex share an oncodevelopmental antigen with embryonic kidney and Wilms' tumor. Am J Pathol 1988;133:596-608.

9 Figarella-Branger DF, Durbec PL, Rougon GN. Differential spectrum of expression of neural cell adhesion molecule isoforms and $\mathrm{L} 1$ adhesion molecules on neuroectodermal tumors. Cancer Res 1990;50:6364-70.

10 Schwab M, Alitalo K, Klempnauer KK, et al. Amplified DNA with limited homology to myc cellular oncogene is shared by human neuroblastoma cell lines and neuroblastoma tumour. Nature 1983;305:245-8.

11 Tumilowicz JT, Nichols WW, Cholon JJ, Green AE. Definition of a continuous human cell line derived from Definition of a continuous human cell line der.

12 Biedler JL, Helson L, Spengler BA. Morphology and growth, tumorigenicity and cytogenetics of human growth, tumorigenicity and cytogenetics of human 1973;33:2643-52.

13 Imashuku S, Innui A, Nakamura T, Tanaka J, Miyake S. Catecholamine metabolism in tissue culture cell lines of a neuroblastoma. J Clin Endocrinol Metab 1973;36:931-6.

14 Sekiguchi M, Oota T, Sakakibara K, Inue N, Fujii G. Establishment and characterisation of a neuroblastoma cell line in tissue culture. Jpn J Exp Med 1979;49:67-83.

15 Schlesinger HR, Gerson JM, Moorhead PS, Maguire H, Hummeler K. Establishment and characterisation of 3094-100.

16 Minowada J, Dnuma T, Moore GE. Brief communication: rosette-forming human lymphoid cell lines. I. Establishment and evidence for origin of thymus-derived lymment and evidence for origin

17 Allan PM, Garson JA, Harper EI. Biological characterization and clinical applications of a monoclonal antibody tion and clinical applications of a monoclonal antibody recognizing an antigen restricted
tissues. Int $J$ Cancer 1983;31:501-8.

18 Bourne SP, Patel K, Walsh FS, Popham CJ, Coakham HB, Kemshead JT. A monoclonal antibody (ERIC-1), raised against retinoblastoma, that recognizes the neural cell adhesion molecule (NCAM) expressed on brain and tumours arising from the neuroectoderm. J Neuro-Oncol 1991:(In Press).

19 Patel K, Moore SE, Dickson G, et al. Neural cell adhesion molecule (NCAM) is the antigen recognized by monoclonal antibodies of similar specificity in small cell lung carcinoma and neuroblastoma. Int J Cancer 1989;44: 573-8.

20 Kemshead JT, Goldman A, Fritschy J, Malpas JS, Pritchard J $J$. The use of panels of monoclonal antibodies in the
differential diagnosis of neuroblastoma and lymphoblastic differential diagnosis of neuroblar.

21 Kemshead JT, Heath L, Gibson F, et al. Magnetic microspheres and monoclonal antibodies for the depletion of neuroblastoma cells from bone marrow. Experiences, improvements and observations. $B r J$ Cancer 1986;54 $771-8$

22 Favrot M, Frappez D, Maritaz O, et al. Histological, cytological and immunological analysis are complementary for the detection of neuroblastoma cells in bone marrow. Br J Cancer 1986;54:636-41.

23 Oppedal BR, Storm-Mathisen I, Kemshead JT, Brandzaeg P. Bone marrow examinations in neuroblastoma patients. Hum Pathol 1989;20:800-5.

24 Frost G, Patel K, Bourne S, Coakham HB, Kemshead JT Expression of alternative isoforms of the neural cell axpression of alternative isoforms of the neural variety adhesion molecule (NCAM) on normal brain and a variety

25 Kadmon G, Kowitz A, Altevogt P, Schachner M. The neural cell adhesion molecule NCAM enhances L1-dependent cell-cell interations. J Cell Biol 1990;110:193-208. 